\title{
Adiposity is Associated with Decreased Serum 17-Hydroxyprogesterone Levels in Non-Diabetic Obese Men Aged 18-49: A Cross-Sectional Study
}

\author{
José Ignacio Martínez-Montoro ${ }^{1}$ D, María Molina-Vega 1,2,*(D), Maite Asenjo-Plaza ${ }^{3}$, \\ María Concepción García-Ruiz ${ }^{3}$, Enrique Varea-Marineto ${ }^{3}$, Isaac Plaza-Andrade ${ }^{2}$, \\ Juan J. Álvarez-Millán ${ }^{4}$, Pablo Cabezas-Sánchez ${ }^{4}$, Francisco J. Tinahones 1,2,5,* \\ and José Carlos Fernández-García 1,2,5,6 (D) \\ 1 Department of Endocrinology and Nutrition, Virgen de la Victoria University Hospital, 29010 Málaga, Spain; \\ joseimartinezmontoro@gmail.com (J.I.M.-M.); josecarlosfdezgarcia@hotmail.com (J.C.F.-G.) \\ 2 Laboratorio de Investigación, Instituto de Investigación Biomédica de Málaga (IBIMA), 29010 Málaga, Spain; \\ isaacplazaandrade@gmail.com \\ 3 Cruz de Humilladero Primary Care Centre, 29006 Málaga, Spain; maite.asenjo.plaza@gmail.com (M.A.-P.); \\ adagaru60@gmail.com (M.C.G.-R.); envarneto@hotmail.com (E.V.-M.) \\ 4 Consulting Químico Sanitario (CQS Lab), 28521 Madrid, Spain; jamillan@cqslab.com (J.J.Á.-M.); \\ pcabezas@cqslab.com (P.C.-S.) \\ 5 Centro de Investigación Biomédica en Red de la Fisiopatología de la Obesidad y Nutrición (CIBEROBN), \\ Instituto de Salud Carlos III (ISCIII), 28029 Madrid, Spain \\ 6 Endocrinology and Nutrition Department, Regional University Hospital of Malaga, 29010 Malaga, Spain \\ * Correspondence: molinavegamaria@gmail.com (M.M.-V.); fjtinahones@hotmail.com (F.J.T.); \\ Tel.: +34951034016 (M.M.-V. \& F.J.T.); Fax: +34951924651 (M.M.-V. \& F.J.T.)
}

Received: 30 September 2020; Accepted: 26 November 2020; Published: 28 November 2020

\begin{abstract}
Obesity is associated with decreased circulating testosterone levels, the main male sex hormone. However, there are a number of different male sex hormones whose dynamics remain poorly understood regarding this pathology. In this regard, 17 hydroxyprogesterone (17-OH progesterone), as an important precursor of testosterone synthetized in testes and adrenal glands, could play an essential role in testosterone deficiency in male obesity. Moreover, similarly to testosterone, 17-OH progesterone could be closely associated with visceral fat distribution and metabolic dysfunction. Thus, the aim of this study was to assess serum 17-OH progesterone levels in non-diabetic obese young men and to evaluate their relationship with clinical, analytical, and anthropometric parameters. We conducted a cross-sectional study including 266 non-diabetic men with obesity (BMI $\geq 30 \mathrm{~kg} / \mathrm{m}^{2}$ ) aged $18-49$ years; $17-\mathrm{OH}$ progesterone and total testosterone (TT) were determined by high-performance liquid chromatography mass spectrometry. 17-OH progesterone levels were significantly lower in tertile 3 of body fat percentage in comparison with tertile $1(0.74 \mathrm{ng} / \mathrm{mL}$ vs. $0.94 \mathrm{ng} / \mathrm{mL}, p<0.01$; Bonferroni correction) and in comparison with tertile 2 $(0.74 \mathrm{ng} / \mathrm{mL}$ vs. $0.89 \mathrm{ng} / \mathrm{mL}, p=0.02$; Bonferroni correction). $17-\mathrm{OH}$ progesterone levels correlated negatively with weight, BMI, waist circumference, insulin, homeostatic model assessment of insulin resistance (HOMA-IR), and visceral fat, and positively with TT, free testosterone (FT), luteinizing hormone, and fat-free mass percentage. Multivariate linear-regression analysis showed that body fat percentage and HOMA-IR were inversely associated with $17-\mathrm{OH}$ progesterone levels, while FT and ACTH were positively linked to circulating $17-\mathrm{OH}$ progesterone levels. In conclusion, in a population of non-diabetic obese young men, 17-OH progesterone levels were inversely associated with adiposity. Body fat percentage and insulin resistance were negatively related to 17-OH progesterone levels, whereas FT and ACTH levels were positively associated with 17-OH progesterone levels.
\end{abstract}


Keywords: obesity; visceral fat; 17-hydroxyprogesterone; hypogonadism

\section{Introduction}

Overweight and obesity worldwide prevalence has increased in pandemic dimensions in the last few decades. Globally, the estimated number of overweight and obese adults in 2015 was 1.9 billion and 609 million, respectively, which represents 39\% of the world's population [1]. Obesity is associated with a major number of comorbidities, such as type 2 diabetes, cardiovascular disease, cancer, or obstructive sleep apnea [2]. It is also considered the most frequent cause of male hypogonadism [3]. The prevalence of male hypogonadism has been reported to be more than $40 \%$ in obese males [4]. Although some conditions usually associated with obesity, such as type 2 diabetes or cardiovascular disease, are closely linked to testosterone decrease, even in young obese men without these comorbidities, the prevalence of hypogonadism remains high, affecting more than $25 \%$ of these subjects. Moreover, the hypogonadism prevalence rises $>75 \%$ in males with extreme obesity [5].

Androgens play a major role in sexual development and function. Although testosterone is the main circulating male hormone, there are other testicular and adrenal androgenic steroids whose role remains uncertain. In this line, 17-hydroxyprogesterone (17-OH progesterone) is a $\mathrm{C}_{21}$ steroid derived from progesterone via 17 -hydroxylase or 17 -hydroxypregnenolone via $3 \beta$-hydroxysteroid dehydrogenase/ $\Delta 5-4$ isomerase, that acts as intermediate in the biosynthesis of hydrocortisone and gonadal steroid hormones [6]. In men, most serum $17-\mathrm{OH}$ progesterone has a testicular and not adrenal origin; approximately $70 \%$ of $17-\mathrm{OH}$ progesterone is synthetized in testes, while the remaining production comes from adrenal glands. Similar to testosterone, $17-\mathrm{OH}$ progesterone is stimulated by the luteinizing hormone (LH) and the human chorionic gonadotropin (hCG) [7-9]. Decreased serum testosterone levels in obesity are linked to reduced $\mathrm{C}_{19}$ steroids biosynthesis and potentially, this reduction could carry an altered metabolic risk profile [10,11].

Accordingly, a compromised synthesis of $\mathrm{C}_{21}$ steroid $17-\mathrm{OH}$ progesterone could constitute a previous step in the impaired $\mathrm{C}_{19}$ steroids and testosterone production in obese men. However, the lack of knowledge about the specific role of $17-\mathrm{OH}$ progesterone has motivated several hypotheses, mainly connected to spermatogenesis and fertility. Moreover, as 17-OH progesterone is the second-most important intratesticular steroid in percentage after testosterone, and given the variability between serum testosterone levels and intratesticular testosterone levels, some authors have proposed that circulating $17-\mathrm{OH}$ progesterone could be a more useful serum marker for intratesticular testosterone concentrations and might be helpful to monitor patients receiving hormonal treatment for male infertility and to titrate the dose of medication $[12,13]$.

In contrast to the well-documented relationship between obesity and serum testosterone levels, there is limited knowledge about $17-\mathrm{OH}$ progesterone dynamics in obese subjects. In this regard, previous studies have reported decreased circulating levels of different androgens and their precursors in obese men, including $17-\mathrm{OH}$ progesterone, although none of them were specifically focused on this steroid hormone and they only measured this parameter in a reduced number of participants [14-16]. Moreover, the presence of type 2 diabetes, cardiovascular disease, or aging could constitute confounding variables in the evaluation of $17-\mathrm{OH}$ progesterone. Furthermore, the assessment of body composition analysis in these patients could shed light about the relationship between 17-OH-progesterone and adiposity.

Hence, in the present work we aimed to assess the dynamics of $17-\mathrm{OH}$ progesterone in nondiabetic obese young men and to evaluate if their circulating levels are decreased in parallel to adiposity. Also, we evaluated the relationship between $17-\mathrm{OH}$ progesterone concentrations with clinical, analytical, and anthropometric parameters. 


\section{Experimental Section}

\subsection{Study Design and Participants}

This was a cross-sectional study, done at the Virgen de la Victoria University Hospital (Malaga, Spain), from June 2013 to June 2015. Men with obesity (BMI $\geq 30 \mathrm{~kg} / \mathrm{m}^{2}$ ) aged 18-49 years old were included in this study. Those men with a previous diagnosis of hypoandrogenemia, diabetes mellitus (diagnosed if a potential participant was taking medication for diabetes, had fasting plasma glucose $\geq 126 \mathrm{mg}$ per deciliter ( $7 \mathrm{mmol}$ per liter)), or $\mathrm{HbA} 1 \mathrm{c} \geq 6.5 \%$, as confirmed by repeated testing), use of any antidiabetic medication, or being under any treatment known to affect the gonadal axis, including any form of testosterone were excluded. The existence of hepatic impairment (total bilirubin levels $>2 \mathrm{mg} / \mathrm{dL}$ or aspartate amino transferase levels three times higher than the normal upper limit) or renal impairment (estimated glomerular filtration rate $<60 \mathrm{~mL} / \mathrm{min} / 1.73 \mathrm{~m}^{2}$ or albumin to creatinine ratio $\geq 30 \mathrm{mg} / \mathrm{g}$ ), established cardiovascular disease (defined as documented ischemic heart disease, cerebrovascular disease, or peripheral arterial disease) or previous history of cancer (except basalioma), or active cancer of any kind was also exclusion criteria.

\subsection{Biochemical Evaluation}

Blood samples were collected from all participants between 08:00 and 10:00 after 10 h of fasting. Study participants were instructed to eat a light meal the evening before. Samples were centrifuged and plasma and serum were distributed in aliquots and stored at $-80^{\circ} \mathrm{C}$ until analysis.

In order to obtain age, medical history, and current diseases and associated treatment, a structured interview was completed by participants. We also collected weight and height (to calculate BMI) and waist circumference (WC). Biochemical parameters were measured in duplicate using standard enzymatic methods. Homeostatic model assessment of insulin resistance (HOMA-IR), as described by Mathews et al. [17] was used to determine insulin resistance. High-sensitivity C-reactive protein (hs-CRP) was analyzed in a multiplex immunoassay platform, Adrenocorticotropic hormone (ACTH) was measured in EDTA (ethylenediaminetetraacetic acid) plasma using a two-site sequential chemiluminescent immunometric assay (reference values $5-50 \mathrm{pg} / \mathrm{mL}$ ). Luteinizing hormone $(\mathrm{LH})$ was determined using a direct quimiluminometric assay (reference values $1.5-7.7 \mathrm{mIU} / \mathrm{mL}$ ). Total testosterone (TT) was determined by high-performance liquid chromatography mass spectrometry (HPLC-MS), details about its determination can be found elsewhere [5]. Sex-hormone-binding globulin was determined with an electrochemiluminescence immunoassay (reference range $15-50 \mathrm{nmol} / \mathrm{L}$ ) and free testosterone (FT) was calculated from TT and sex-hormone-binding globulin using a law-of-mass-action equation [18]. 17-OH progesterone was determined by HPLC-MS conducted in a triple quadrupole liquid chromatography mass spectrometry system (Model 6460; Agilent Technologies, Santa Clara, California). The lower limit of detection was $0.062 \mathrm{ng} / \mathrm{mL}$, the interassay coefficient of variation was $2.66 \%$ at $0.30 \mathrm{ng} / \mathrm{mL}, 3.89 \%$ at $1.46 \mathrm{ng} / \mathrm{mL}$, and $0.76 \%$ at $8.97 \mathrm{ng} / \mathrm{mL}$, and the intraassay coefficient of variation was $2.18 \%$ at $0.30 \mathrm{ng} / \mathrm{mL}, 4.19 \%$ at $1.46 \mathrm{ng} / \mathrm{mL}$, and $1.77 \%$ at $8.97 \mathrm{ng} / \mathrm{mL}$. Accuracy was $102 \%$, and recovery was $92 \%$. The calibrators were human serum samples. The material was lyophilized and contained six levels of $0.097,0.48,0.961,1.95,3.85$, and $21.6 \mathrm{ug} / \mathrm{L}$ and a blank. Quality control (QC) samples were prepared from different stock solution at three levels of human serum samples $(0.3$, 1.46 , and $8.970 \mathrm{ug} / \mathrm{L}$ serum concentration). Working calibrations and QC were reconstituted with $3 \mathrm{~mL}$ of distilled water into each vial and incubated $15 \mathrm{~min}$ at room temperature. The vials were swirled to dissolve the contents until homogeneity. The HPLC-MS system was controlled with the Agilent MassHunter Workstation software version B.06.00 (Agilent, Santa Clara, CA, USA). For peak integration and quantitative calculation, the Agilent MassHunter Quantitative Analysis software version B.06.00 was used. 


\subsection{Body Composition Analysis}

The Tanita Multi-Frequency Body Composition Analyzer MC-180MA (Tanita Corporation, Tokyo, Japan), a weighing instrument that uses bioelectrical impedance analysis to screen body fat and composition, was used to assess body composition. This instrument had been validated against other weighing methods and was repeatedly checked in relation to the reference standards of dual-energy X-ray absorptiometry (DEXA) [19].

Fat mass and fat-free mass were measured. Visceral fat was indirectly estimated and results were given as a specific rating-visceral fat rating (VFR; $0 \pm 59$; no units). A rate of $1-12$ is considered healthy while a rate of 13-59 indicates an excess level of visceral fat. VFR is extensively used in medical research for indirect visceral fat measurement in adults [20].

\subsection{Ethics}

This study was reviewed and approved by the Ethics and Research Committee of Virgen de la Victoria Clinical University Hospital, Málaga, Spain on 12 December 2012 (Ethics Committee Code CMCS240281) and was conducted according to the principles of the Declaration of Helsinki. The participants (who were all volunteers) provided signed consent after being fully informed of the study goal and its characteristics.

\subsection{Statistical Analysis}

Statistical analyses were performed using the IBM SPSS Statistics version 25.0 (IBM Corporation, Armonk, NY, USA). An ANOVA test followed by a Bonferroni post-hoc test was used to compare basal characteristics of the subgroups. We performed a Pearson's correlation test to evaluate the relationships among the selected variables. Multivariate linear regression analysis was used to examine the associations of demographic, physical, medical, and biochemical factors with $17-\mathrm{OH}$ progesterone levels. Those variables with a $p$ value $<0.25$ in the bivariate model were entered in the multivariate model, and a parsimonious multivariate lineal regression model was constructed, taking into account multicollinearity (through the variance inflation factor). The best model was selected according to the Akaike information criterion, and models with multicollinearity were excluded. Statistical significance was established for $p$-values $<0.05$.

\section{Results}

\subsection{Study Population}

We included 266 non-diabetic adult obese men $<50$ years in this study. However, according to serum $17-\mathrm{OH}$ progesterone levels, we excluded 13 subjects due to increased circulating levels of $17-\mathrm{OH}$ progesterone above the reference range $(>2 \mathrm{ng} / \mathrm{mL}(6.06 \mathrm{nmol} / \mathrm{L}))$, because these abnormal results cannot completely exclude non-classic congenital adrenal hyperplasia diagnosis, in compliance with literature-established normal ranges according to age and gender [21-23]. Thus, the final sample for this study comprised 253 non-diabetic obese men $<50$ years.

\subsection{Characteristics of the Study Population}

Comparative analysis of clinical characteristics and laboratory parameters of participants according to tertiles of body fat percentage is shown in Table 1. Briefly, in addition to the expected significant increase in BMI, VFR, glucose, HbA1c, hs-CRP, and insulin resistance with increasing body fat percentage, we found that not only TT and FT, but also mean 17-OH progesterone levels, significantly decreased across the body fat percentage continuum. Serum levels of $17-\mathrm{OH}$ progesterone were significantly different between tertiles of body fat percentage $(p<0.001)$. Specifically, mean circulating 17-OH progesterone concentrations were significantly lower in tertile 3 of body fat percentage in comparison with tertile $1(0.74 \mathrm{ng} / \mathrm{mL}$ vs. $0.94 \mathrm{ng} / \mathrm{mL}, p<0.01$; Bonferroni correction) and tertile 2 
$(0.74 \mathrm{ng} / \mathrm{mL}$ vs. $0.89 \mathrm{ng} / \mathrm{mL}, p=0.02$; Bonferroni correction). No differences were found between tertile 1 and tertile 2 of body fat percentage $(0.89 \mathrm{ng} / \mathrm{mL}$ vs. $0.94 \mathrm{ng} / \mathrm{mL}, p=0.638)$. Similar results were found when we evaluated the relationship between the BMI classification and clinical characteristics/laboratory parameters (Supplemental Table S1). In addition, a comparative analysis of 17-OH progesterone levels by tertiles of different measures of adiposity (BMI, WC, and VFR), found decreased 17-OH progesterone levels with the increment of these adiposity markers (Table 2).

Table 1. Characteristics of the study population according to tertiles of body fat percentage.

\begin{tabular}{|c|c|c|c|c|}
\hline & $\begin{array}{c}\text { Tertile } 1 \\
(n-84)\end{array}$ & $\begin{array}{c}\text { Tertile } 2 \\
(n-84)\end{array}$ & $\begin{array}{c}\text { Tertile } 3 \\
(n-85)\end{array}$ & $p$ Value \\
\hline Age (years) & $38.4 \pm 6.3$ & $36 \pm 8.5$ & $36.2 \pm 7.6$ & 0.320 \\
\hline Weight (kg) & $103.4 \pm 10.2^{\mathrm{a}}$ & $117.7 \pm 11.3^{b}$ & $141.4 \pm 17.8^{c}$ & $<0.001$ \\
\hline $\mathrm{BMI}\left(\mathrm{kg} / \mathrm{m}^{2}\right)$ & $33.2 \pm 2.8^{\mathrm{a}}$ & $37.3 \pm 2.5^{\mathrm{b}}$ & $46.8 \pm 5.6^{c}$ & $<0.001$ \\
\hline $\mathrm{WC}(\mathrm{cm})$ & $111.2 \pm 5.7^{\mathrm{a}}$ & $121.5 \pm 7.7^{b}$ & $140.8 \pm 12.3^{c}$ & $<0.001$ \\
\hline Fat mass (kg) & $29.2 \pm 3.7^{a}$ & $40.1 \pm 4.7^{b}$ & $59.4 \pm 11.9^{c}$ & $<0.001$ \\
\hline Fat mass $(\%)$ & $28.2 \pm 2.1^{a}$ & $34 \pm 1.2^{b}$ & $41.6 \pm 3.4^{c}$ & $<0.001$ \\
\hline Fat-free mass (kg) & $72.9 \pm 5.6^{\mathrm{a}}$ & $77.1 \pm 7.1^{b}$ & $81.8 \pm 7.3^{c}$ & $<0.001$ \\
\hline Fat- free mass (\%) & $70.7 \pm 3.7^{\mathrm{a}}$ & $65.5 \pm 1.8^{b}$ & $58.2 \pm 3.4^{c}$ & $<0.001$ \\
\hline VFR (points) & $12.6 \pm 2^{a}$ & $16.7 \pm 2.5^{b}$ & $26.1 \pm 5.4^{c}$ & $<0.001$ \\
\hline Glucose (mg/dL) & $90.7 \pm 8.2^{\mathrm{a}}$ & $92.6 \pm 11.2^{\mathrm{a}, \mathrm{b}}$ & $94.5 \pm 9.8^{b}$ & 0.048 \\
\hline $\mathrm{HbA} 1 \mathrm{c}(\%)$ & $5.3 \pm 0.3^{a}$ & $5.4 \pm 0.4^{\mathrm{a}}$ & $5.5 \pm 0.4^{b}$ & 0.035 \\
\hline Triglycerides (mg/dL) & $150.7 \pm 81.1$ & $149 \pm 75.8$ & $157.5 \pm 83.5$ & 0.773 \\
\hline HDL-c (mg/dL) & $42.3 \pm 7.6$ & $42.2 \pm 10.4$ & $41.1 \pm 9.5$ & 0.676 \\
\hline LDL-c (mg/dL) & $118 \pm 28$ & $112 \pm 31.4$ & $110.5 \pm 29.4$ & 0.229 \\
\hline hs-CRP (mg/dL) & $1.6 \pm 1.9^{\mathrm{a}}$ & $2.9 \pm 4.5^{\mathrm{a}}$ & $5.7 \pm 8.5^{b}$ & $<0.001$ \\
\hline Insulin (uIU/mL) & $13.5 \pm 6.4^{\mathrm{a}}$ & $20 \pm 13.2^{b}$ & $27.1 \pm 21.5^{c}$ & $<0.001$ \\
\hline HOMA-IR & $3.1 \pm 1.6^{\mathrm{a}}$ & $4.8 \pm 3.9^{b}$ & $6.5 \pm 6^{c}$ & $<0.001$ \\
\hline ACTH $(\mathrm{pg} / \mathrm{mL})$ & $25.2 \pm 15.9$ & $27 \pm 14.2$ & $29.7 \pm 15.1$ & 0.172 \\
\hline $\mathrm{LH}(\mathrm{mUI} / \mathrm{mL})$ & $3.8 \pm 1.7$ & $4 \pm 2.7$ & $3.5 \pm 1.7$ & 0.371 \\
\hline TT (ng/mL) & $4.1 \pm 1.4^{\mathrm{a}}$ & $3.8 \pm 1.2^{\mathrm{a}}$ & $3.2 \pm 1.2^{b}$ & $<0.001$ \\
\hline FT $(\mathrm{pg} / \mathrm{mL})$ & $94.6 \pm 28.3^{a}$ & $92.3 \pm 27.7^{\mathrm{a}}$ & $77.7 \pm 24.5^{b}$ & $<0.001$ \\
\hline 17-OH progesterone $(\mathrm{ng} / \mathrm{mL})$ & $0.94 \pm 0.4^{\mathrm{a}}$ & $0.89 \pm 0.33^{\mathrm{a}}$ & $0.74 \pm 0.31^{b}$ & $<0.001$ \\
\hline
\end{tabular}

Values are presented as mean \pm SD (standard deviation). $p$ values were calculated for differences between groups using ANOVA test, considering $p<0.05$ significant. Means denoted by a different letter indicate significant differences between groups $(p<0.05)$. BMI, body mass index; WC, waist circumference; VFR, visceral fat rating; $\mathrm{HbA1c}$, hemoglobin A1c; HDL-c, high-density lipoprotein cholesterol; LDL-c, low-density lipoprotein cholesterol; hs-CRP, high-sensitivity C-reactive protein; HOMA-IR, homeostatic model assessment of insulin resistance; ACTH, adrenocorticotrophic hormone; LH, luteinizing hormone; TT, total testosterone; FT, free testosterone. Reference intervals: ACTH, 5-50 pg/mL; LH, 1.5-7.7 mUI /mL; TT, $\geq 3.5 \mathrm{ng} / \mathrm{mL} ; \mathrm{FT}, \geq 70 \mathrm{pg} / \mathrm{mL} ; 17-\mathrm{OH}$ progesterone, $\leq 2 \mathrm{ng} / \mathrm{mL}$.

Table 2. 17-Hydroxyprogesterone levels $(\mathrm{ng} / \mathrm{mL})$ by tertiles of different measures of adiposity.

\begin{tabular}{cccc}
\hline Tertile 1 & Tertile 2 & Tertile 3 & $p$ Value \\
\hline BMI 0.94 $\pm 0.38^{\text {a }}$ & $0.88 \pm 0.33^{\mathrm{a}}$ & $0.73 \pm 0.36^{\mathrm{b}}$ & $<0.001$ \\
WC $0.94 \pm 0.36^{\mathrm{a}}$ & $0.89 \pm 0.35^{\mathrm{a}}$ & $0.71 \pm 0.31^{\mathrm{b}}$ & $<0.001$ \\
VFR 0.93 $\pm 0.39^{\mathrm{a}}$ & $0.91 \pm 0.34^{\mathrm{a}}$ & $0.70 \pm 0.36^{\mathrm{b}}$ & $<0.001$ \\
\hline
\end{tabular}

Values of 17-hydroxyprogesterone are presented as mean \pm SD. $p$ values were calculated for differences between groups using ANOVA test, considering $p<0.05$ significant. Means denoted by a different letter indicate significant differences between groups $(p<0.05)$. BMI, body mass index; WC, waist circumference; VFR, visceral fat rating.

\subsection{Correlation Analysis between 17-OH Progesterone and Other Variables}

A significant negative correlation was detected between serum $17-\mathrm{OH}$ progesterone and weight $(p<0.001)$, body fat (kg and percentage $(p<0.001))$, BMI $(p<0.001)$, WC $(p<0.01)$, VFR $(p<0.001)$, insulin $(p<0.001)$, and HOMA-IR $(p<0.001)$. A significant positive correlation was found between serum 17-OH progesterone and LH $(p=0.001)$, fat-free mass percentage $(p=0.001)$, and TT and 
FT $(p<0.001)$ (Table 3). Also, the correlation coefficient between 17-OH progesterone and FT was determined to be 0.450 , while the correlation coefficient between $17-\mathrm{OH}$ progesterone and TT was 0.537 .

Table 3. Correlation coefficients among 17-OH progesterone and anthropometric, biochemical, and hormonal parameters.

\begin{tabular}{ccc}
\hline & \multicolumn{2}{c}{ 17-OH Progesterone } \\
\cline { 2 - 3 } & $\mathbf{r}$ & $\boldsymbol{p}$ Value \\
\hline Age (years) & -0.120 & 0.058 \\
Weight $(\mathrm{kg})$ & -0.245 & $<0.001$ \\
BMI $\left(\mathrm{kg} / \mathrm{m}^{2}\right)$ & -0.299 & $<0.001$ \\
WC $(\mathrm{cm})$ & -0.297 & $<0.001$ \\
VFR (points) & -0.322 & $<0.001$ \\
Fat mass (kg) & -0.284 & $<0.001$ \\
Fat mass (\%) & -0.290 & $<0.001$ \\
Fat-free mass $(\%)$ & 0.270 & $<0.001$ \\
Glucose (mg/dL) & -0.086 & 0.171 \\
Insulin (uIU/mL) & -0.256 & $<0.001$ \\
HOMA-IR & -0.243 & $<0.001$ \\
hs-CRP (mg/dL) & -0.095 & 0.137 \\
ACTH (pg/mL) & 0.077 & 0.232 \\
LH (mUI/mL) & 0.214 & 0.001 \\
TT (mg/dL) & 0.537 & $<0.001$ \\
FT (pg/mL) & 0.450 & $<0.001$ \\
\hline
\end{tabular}

Bold values mean significant statistical association in Pearson's correlation test. BMI, body mass index; WC, waist circumference; VFR, visceral fat rating; HOMA-IR, homeostatic model assessment of insulin resistance; hs-CRP, high-sensitivity C-reactive protein; ACTH, adrenocorticotrophic hormone; LH, luteinizing hormone; FT, free testosterone; TT, total testosterone.

\subsection{Factors Associated with 17-OH Progesterone Levels}

We performed a multiple linear regression analysis to explore factors associated with serum 17-OH progesterone levels (Table 4). The model that best explained serum 17-OH progesterone levels comprised age, body fat percentage, ACTH, HOMA-IR, LH, and FT (F test $<0.01$ ), with an adjusted $\mathrm{R}^{2}$ of 0.28 .

Table 4. Multiple linear regression analysis: factors related to 17-OH progesterone levels.

\begin{tabular}{ccccc}
\hline & B (SE) & Beta & T Statistic & $p$ Value \\
\hline Age (years) & $-0.001(0.003)$ & -0.031 & -0.536 & 0.592 \\
Body fat $(\%)$ & $-0.008(0.004)$ & -0.128 & -2.029 & 0.044 \\
ACTH $(\mathrm{pg} / \mathrm{mL})$ & $0.003(0.001)$ & 0.125 & 2.158 & 0.032 \\
HOMA-IR & $-0.012(0.005)$ & -0.148 & -2.514 & 0.013 \\
LH $(\mathrm{mUI} / \mathrm{mL})$ & $0.017(0.010)$ & 0.102 & 1.771 & 0.078 \\
FT $(\mathrm{pg} / \mathrm{mL})$ & $0.005(0.001)$ & 0.382 & 6.020 & $<0.001$ \\
\hline
\end{tabular}

Unstandardized coefficients (B) of the linear regression model with SE, standardized coefficients (Beta), T Statistic, and $p$ values. ACTH, adrenocorticotrophic hormone; HOMA-IR, homeostatic model assessment of insulin resistance; $\mathrm{LH}$, luteinizing hormone; FT, free testosterone.

Body fat percentage (Beta $-0.128, p=0.04$ ) and HOMA-IR (Beta $-0.148, p=0.013$ ) was inversely associated with $17-\mathrm{OH}$ progesterone levels, whereas FT levels (Beta 0.382, $p<0.001$ ) and ACTH concentrations (Beta $0.125, p=0.032$ ) were positively linked to $17-\mathrm{OH}$ progesterone levels. On the other hand, neither age nor LH levels influenced serum 17-OH progesterone levels (Table 3). 


\section{Discussion}

Our results reveal that circulating $17-\mathrm{OH}$ progesterone levels decrease in parallel with the increase of body fat percentage in non-diabetic young men with obesity. Also, we found that $17-\mathrm{OH}$ progesterone concentrations were independently related to visceral fat, insulin resistance, FT and ACTH levels.

Obesity, particularly when associated with visceral adiposity accumulation, has a major influence on androgen metabolism, with different implications with respect to sex; obesity in men is associated with a decrease of testosterone, whereas obese women are prone to developing functional hyperandrogenism [24]. While the relationship between low serum testosterone levels and male obesity is firmly established $[4,5,25,26]$ the dynamics of distinct adrenal and gonadal androgens in obesity, specifically $17-\mathrm{OH}$ progesterone, have attracted less interest.

In agreement with the preceding research, our results showed decreased serum $17-\mathrm{OH}$ progesterone concentrations in obese men. Importantly, previous studies presented a reduced sample size and were focused on different circulating hormones in obesity, but included $17-\mathrm{OH}$ progesterone as part of their analyses. Blanchette et al. [14] detected a negative correlation between 17-OH progesterone and BMI in a population of 38 lean to morbidly-obese men between 23 and 61 years old. Isidori et al. [15] investigated leptin impact on several androgens in 28 obese men aged 18-58 years matched with 10 non-obese controls, finding significant differences between both obese men vs. non-obese controls and moderately obese men (BMI $\left.30-40 \mathrm{~kg} / \mathrm{m}^{2}\right)$ vs. morbidly obese men $\left(>40 \mathrm{~kg} / \mathrm{m}^{2}\right)$ in $17-\mathrm{OH}$ progesterone levels. In addition, they also found a significant negative correlation between BMI and 17-OH progesterone levels. These results were concordant with those found by Damgaard-Olesen et al., who showed significantly-lower mean serum $17-\mathrm{OH}$ progesterone levels when compared to obese, overweight, and normal-weight subjects [16]. Moreover, similarly to that observed by us, they did not find significant associations with age for $17-\mathrm{OH}$ progesterone.

Low testosterone levels in obesity have been widely reported before, as obesity is the most prevalent cause of hypogonadotropic hypogonadism [3]. Our study population presented progressively-decreased levels of both TT and FT according to the tertiles of body fat percentage. Similarly, serum 17-OH progesterone levels were significantly lower in the tertile 3 of body fat percentage. Besides, $17-\mathrm{OH}$ progesterone levels were shown to be positively associated with circulating TT and FT levels in the correlation analysis, as well as with LH. FT and ACTH were independently-associated factors predicting serum $17-\mathrm{OH}$ progesterone levels in the linear regression analysis. Our findings may suggest that $17-\mathrm{OH}$ progesterone levels follow a similar pattern to testosterone concentrations in obesity and that a connection between the deficiency of these two hormones in obesity could exist. In this line, we hypothesize there are two main mechanisms linking obesity to low serum $17-\mathrm{OH}$ progesterone levels (Figure 1). On the one hand, obesity is associated with a global impairment of androgen synthesis by the Leydig cell as a consequence of alterations in gonadotropin secretion [27]. 17-OH progesterone is predominantly produced by the Leydig cells in testes through LH stimulation, and the adrenal glands are responsible for the remaining biosynthesis $[8,9,11]$. Therefore hypothalamic-pituitary-gonadal axis disruption in obesity could trigger a diminished secretion of $17-\mathrm{OH}$ progesterone and testosterone. Furthermore, low serum 17-OH progesterone levels could constitute an early step in conditioning decreased testosterone levels in obesity. It has also been postulated that obesity alters 17-20-lyase activity, the enzyme that converts $17-\mathrm{OH}$ progesterone into testosterone, causing an elevated $17-\mathrm{OH}$ progesterone/testosterone ratio with both decreased $17-\mathrm{OH}$ progesterone and testosterone levels with respect to healthy subjects after LH/hCG stimulation [15], a fact that could reinforce the connection between both androgens.

On the other hand, adrenal synthesis of $17-\mathrm{OH}$ progesterone could be compromised in a similar form. Previous research has demonstrated that there is a decreased C19 steroid production in the adrenal cortex in obese men [13]. A study reported elevated leptin levels in obesity can dysregulate the hypothalamic-pituitary-adrenal axis at adrenal level, causing reduced steroidogenesis and molecular expression of steroid enzymes, including 17 alpha-hydroxylase activity, the enzyme that converts progesterone to $17-\mathrm{OH}$ progesterone [28]. In light of our results, $17-\mathrm{OH}$ progesterone levels could 
also be influenced by a hypothalamic-pituitary-adrenal axis disturbance at a central level in some obese individuals, in regard to a ACTH-independent association with $17-\mathrm{OH}$ progesterone in the linear regression analysis, which showed a positive link between these two variables. Hence, it must be noted that decreased serum 17-OH progesterone levels in obesity may be explained not only by a gonadal-impaired synthesis, in the same way as the production of several androgens is affected in this condition, but also by the loss of the hypothalamic-pituitary-adrenal axis integrity.

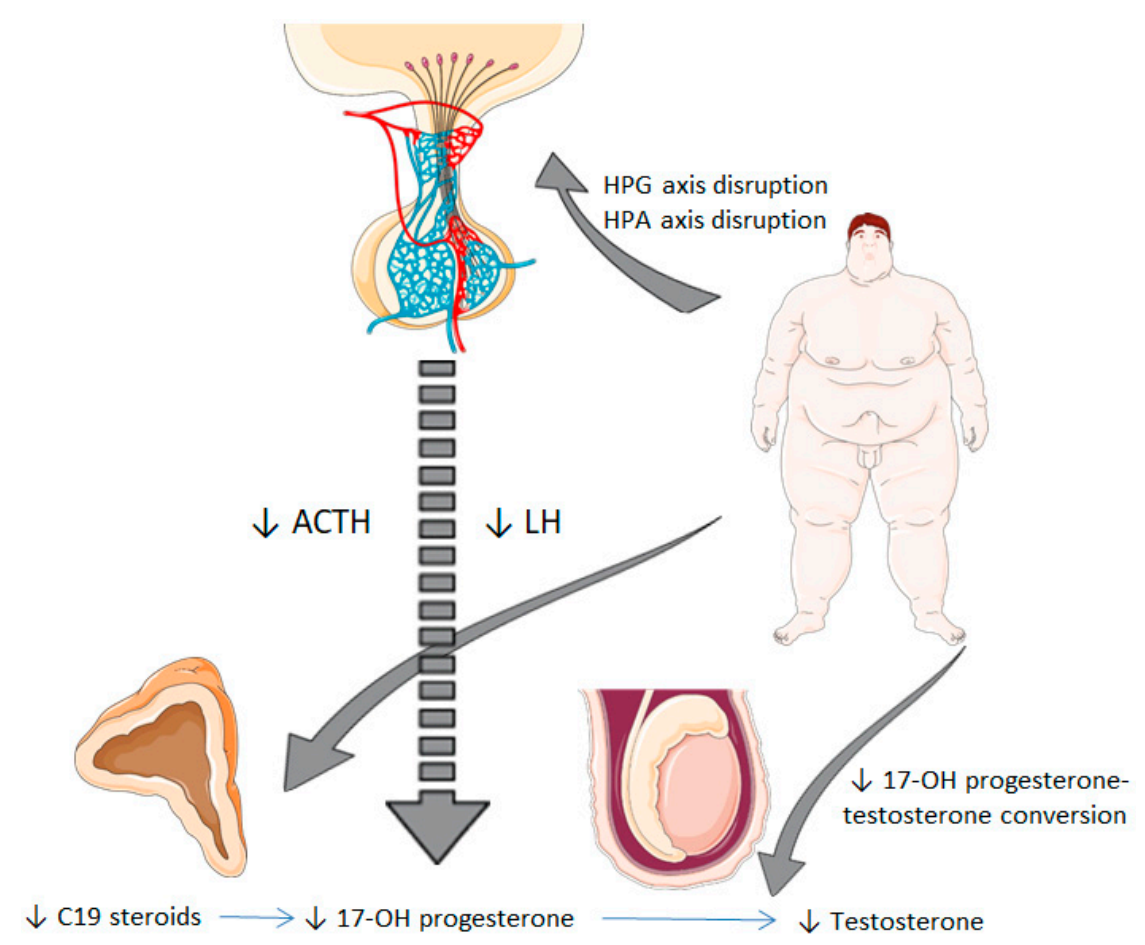

Figure 1. Potential mechanisms from obesity to decreased serum 17-hydroxyprogesterone levels. Obesity is associated with a disruption of the hypothalamic-pituitary-gonadal axis, which involves an impaired synthesis of LH. This fact leads to reduced testicular synthesis of 17-OH progesterone and testosterone. Besides, obesity could also alter the hypothalamic-pituitary-adrenal axis at a central level (impaired secretion of ACTH) and adrenal level (reduced synthesis of C19 steroids), which results in decreased 17-OH progesterone levels. HPG, hypothalamic-pituitary-gonadal; HPA, hypothalamic-pituitary-adrenal; LH: luteinizing hormone; ACTH: adrenocorticotropic hormone; 17-OH progesterone, 17-hydroxyprogesterone.

Circulating 17-OH progesterone levels were negatively associated with several parameters related to metabolic syndrome, as BMI, WC, HOMA-IR, fat mass, and VFR. Indeed, body fat percentage and HOMA-IR predicted 17-OH progesterone concentrations in the linear regression model. Thus, it seems plausible that low 17-OH progesterone levels are not only associated with obesity, but also with the abdominal distribution of fat which is characteristic of the metabolic syndrome. Insulin resistance constitutes another important feature of the metabolic syndrome along with abdominal obesity phenotype, and this condition may lead to decreased serum 17-OH progesterone levels. In a similar fashion, testosterone levels in men correlates with insulin sensitivity [29]. It could be feasible to think of a reciprocal influence between the components associated with the metabolic syndrome and $17-\mathrm{OH}$ progesterone too, in the line of the presumable bidirectional association nature described in testosterone-deficiency models $[22,23,30,31]$. In consequence, $17-\mathrm{OH}$ progesterone could have an impact on body composition and fat distribution, and decreased circulating levels of this hormone in obesity could perpetuate a vicious circle of visceral adiposity accumulation.

The main limitation of our study was the cross-sectional nature of its design, which prevented us from establishing causality. Therefore, our results can only suggest associations and new hypothesis 
which should be corroborated in prospective studies. Another limitation of this study is that our results cannot be extrapolated to women. In this line, although obesity has been associated with an increase in androgen levels in obese women, especially testosterone, in a recent study conducted in obese and nonobese women with polycystic ovary syndrome, obese women had lower 17-OH progesterone levels, as compared with lean women [32]. On the other hand, our main strength is the sample size, since as far as we know, this is the largest study assessing circulating 17-OH progesterone levels in obese men, while previous analyses only included a limited number of participants. Besides, we only included young obese participants without diabetes or chronic diseases, in order to reduce confounding factors in our measurements. Another strength of this study is the determination of $17-\mathrm{OH}$ progesterone and testosterone by HPLC-MS, which is considered the gold standard method to determine steroid levels.

In conclusion, we show that adiposity is associated with notably-decreased serum $17-\mathrm{OH}$ progesterone levels, especially amongst those men with higher body fat percentage. We also report that $17-\mathrm{OH}$ progesterone levels in these subjects are negatively related to body fat percentage and insulin resistance, and positively linked to FT and ACTH levels. Further research is needed to confirm the clinical consequences of these findings.

Supplementary Materials: The following supplemental material is available online: http://www.mdpi.com/20770383/9/12/3873/s1, Supplemental Table S1: Characteristics of the study population according to body mass index (BMI) classification.

Author Contributions: Conceptualization, J.C.F.-G., F.J.T., and J.I.M.-M.; methodology, J.C.F.-G., M.M.-V., M.A.-P., M.C.G.-R., E.V.-M., I.P.-A., J.J.Á.-M., and P.C.-S.; validation, J.C.F.-G. and M.M.-V.; formal analysis, J.C.F.-G. and J.I.M.-M.; writing-original draft preparation, J.I.M.-M. and J.C.F.-G.; writing-review and editing, J.I.M.-M., J.C.F.-G., M.M.-V., and F.J.T.; funding acquisition, J.C.F.-G. and F.J.T. All authors have read and agreed to the published version of the manuscript.

Funding: This study was supported by the "Centros de Investigación Biomédica en Red" (CIBER) of the "Instituto de Salud Carlos III" (ISCIII) (CB06/03/0018) and research grants from the ISCIII (PI18/01160), and co-financed by the European Regional Development Fund (ERFD). JCF-G was supported by a research contract from Servicio Andaluz de Salud (SAS) (B-0003-2017) and MM-V was supported by a Rio Hortega grant from Instituto de Salud Carlos III, Madrid, Spain (CM18/00120). This work was supported in part by a grant from Servicio Andaluz de Salud (PI-0173-2013).The funders had no role in study design, data collection and analysis, decision to publish, or preparation of the manuscript.

Conflicts of Interest: The authors have declared that no competing interests exist.

\section{Abbreviations}

$\begin{array}{ll}\text { ACTH } & \text { Adrenocorticotropic hormone } \\ \text { BMI } & \text { Body mass index } \\ \text { FT } & \text { Free testosterone } \\ \text { HOMA-IR } & \text { Homeostatic model assessment of insulin resistance } \\ \text { HPLC-MS } & \text { High-performance liquid chromatography mass spectrometry } \\ \text { hS-CRP } & \text { High-sensitivity C-reactive protein } \\ \text { LH } & \text { Luteinizing hormone } \\ \text { 17-OHprogesterone } & \text { 17-hydroxyprogesterone } \\ \text { TT } & \text { Total testosterone } \\ \text { VFR } & \text { Visceral fat rating } \\ \text { WC } & \text { Waist circumference }\end{array}$

\section{References}

1. Chooi, Y.C.; Ding, C.; Magkos, F. The epidemiology of obesity. Metabolism 2019, 92, 6-10. [CrossRef]

2. Bray, G.A.; Heisel, W.E.; Afshin, A.; Jensen, M.D.; Dietz, W.H.; Long, M.; Kushner, R.F.; Daniels, S.R.; Wadden, T.A.; Tsai, A.G.; et al. The science of obesity management: An endocrine society scientific statement. Endocr. Rev. 2018, 39, 79-132. [CrossRef] 
3. Saboor Aftab, S.A.; Kumar, S.; Barber, T.M. The role of obesity and type 2 diabetes mellitus in the development of male obesity-associated secondary hypogonadism. Clin. Endocrinol. 2013, 78, 330-337. [CrossRef] [PubMed]

4. Molina-Vega, M.; Muñoz-Garach, A.; Damas-Fuentes, M.; Fernández-García, J.C.; Tinahones, F.J. Secondary male hypogonadism: A prevalent but overlooked comorbidity of obesity. Asian J. Androl. 2018, 20, 531-538.

5. Molina-Vega, M.; Asenjo-Plaza, M.; García-Ruiz, M.C.; Varea-Marineto, E.; Casal-Nievas, N.; Álvarez-Millán, J.J.; Cabezas-Sanchez, P.; Cardona-Díaz, F.; Queipo-Ortuño, M.I.; Castellano-Castillo, D.; et al. Cross-Sectional, Primary Care-Based Study of the Prevalence of Hypoandrogenemia in Nondiabetic Young Men with Obesity. Obesity 2019, 27, 1584-1590. [CrossRef] [PubMed]

6. Hydroxyprogesterone|C21H30O3-PubChem. Available online: https://pubchem.ncbi.nlm.nih.gov/ compound/hydroxyprogesterone (accessed on 25 April 2020).

7. Roth, M.Y.; Lin, K.; Bay, K.; Amory, J.K.; Anawalt, B.D.; Matsumoto, A.M.; Marck, B.T.; Bremner, W.J.; Page, S.T. Serum insulin-like factor 3 is highly correlated with intratesticular testosterone in normal men with acute, experimental gonadotropin deficiency stimulated with low-dose human chorionic gonadotropin: A randomized, controlled trial. Fertil. Steril. 2013, 99, 132-139. [CrossRef] [PubMed]

8. Carlstrom, K.; Stege, R. Adrenocortical function in prostatic cancer patients: Effects of orchidectomy or different modes of estrogen treatment on basal steroid levels and on the response to exogenous adrenocorticotropic hormone. Urol. Int. 1990, 45, 160-163. [CrossRef]

9. Stege, R.; Eriksson, A.; Henriksson, P.; Carlstrom, K. Orchidectomy or oestrogen treatment in prostatic cancer: Effects on serum levels of adrenal androgens and related steroids. Int. J. Androl. 1987, 10, 581-587. [CrossRef]

10. Allan, C.A.; McLachlan, R.I. Androgens and obesity. Curr. Opin. Endocrinol. Diabetes Obes. 2010, 17, $224-232$. [CrossRef]

11. Tchernof, A.; Després, J.-P.; Bélanger, A.; Dupont, A.; Prud'Homme, D.; Moorjani, S.; Lupien, P.J.; Labrie, F. Reduced testosterone and adrenal C19 steroid levels in obese men. Metabolism 1995, 44, 513-519. [CrossRef]

12. Patel, A.; Patel, P.; Bitran, J.; Ramasamy, R. Can serum 17-hydroxyprogesterone and insulin-like factor 3 be used as a marker for evaluation of intratesticular testosterone? Transl. Androl. Urol. 2019, 8, S58-S63. [CrossRef] [PubMed]

13. Amory, J.K.; Coviello, A.D.; Page, S.T.; Anawalt, B.D.; Matsumoto, A.M.; Bremner, W.J. Serum 17-hydroxyprogesterone strongly correlates with intratesticular testosterone in gonadotropin-suppressed normal men receiving various dosages of human chorionic gonadotropin. Fertil. Steril. 2008, 89, 380-386. [CrossRef] [PubMed]

14. Blanchette, S.; Marceau, P.; Biron, S.; Brochu, C.; Tchernof, A. Circulating progesterone and obesity in men. Horm. Metab. Res. 2006, 38, 330-335. [CrossRef] [PubMed]

15. Isidori, A.M.; Caprio, M.; Strollo, F.; Moretti, C.; Frajese, G.; Isidori, A.; Fabbri, A. Leptin and androgens in male obesity: Evidence for leptin contribution to reduced androgen levels. J. Clin. Endocrinol. Metab. 1999, 84, 3673-3680. [CrossRef]

16. Damgaard-Olesen, A.; Johannsen, T.; Holmboe, S.A.; Søeborg, T.; Petersen, J.H.; Andersson, A.-M.; Aadahl, M.; Linneberg, A.; Juul, A. Reference ranges of 17-hydroxyprogesterone, DHEA, DHEAS, androstenedione, total and free testosterone determined by TurboFlow-LC-MS/MS and associations to health markers in 304 men. Clin. Chim. Acta 2016, 454, 82-88. [CrossRef]

17. Matthews, D.R.; Hosker, J.P.; Rudenski, A.S.; Naylor, B.A.; Treacher, D.F.; Turner, R.C. Homeostasis model assessment: Insulin resistance and beta-cell function from fasting plasma glucose and insulin concentrations in man. Diabetologia 1985, 28, 412-419. [CrossRef]

18. Vermeulen, A.; Verdonck, L.; Kaufman, J.M. A critical evaluation of simple methods for the estimation of free testosterone in serum. J. Clin. Endocrinol. Metab. 1999, 84, 3666-3672. [CrossRef]

19. Strain, G.W.; Wang, J.; Gagner, M.; Pomp, A.; Inabnet, W.B.; Heymsfield, S.B. Bioimpedance for severe obesity: Comparing research methods for total body water and resting energy expenditure. Obesity 2008, 16, 1953-1956. [CrossRef]

20. Ayeser, T.; Basak, M.; Arslan, K.; Sayan, I. Investigating the correlation of the number of diagnostic criteria to serum adiponectin, leptin, resistin, TNF-alpha, EGFR levels and abdominal adipose tissue. Diabetol. Metab. Syndr. 2016, 10, 165-169. [CrossRef] 
21. Nordenström, A.; Falhammar, H. Management of endocrine disease: Diagnosis and management of the patient with non-classic CAH due to 21-hydroxylase deficiency. Eur. J. Endocrinol. 2019, 180, R127-R145. [CrossRef]

22. Merke, D.P.; Bornstein, S.R. Congenital adrenal hyperplasia. Lancet 2005, 365, 2125-2136. [CrossRef] 
23. Bachega, T.A.S.S.; Billerbeck, A.E.C.; Marcondes, J.A.M.; Madureira, G.; Arnhold, I.J.P.; Mendonca, B.B. Influence of different genotypes on 17-hydroxyprogesterone levels in patients with nonclassical congenital adrenal hyperplasia due to 21-hydroxylase deficiency. Clin. Endocrinol. 2000, 52, 601-607. [CrossRef] [PubMed]

24. Pasquali, R. Obesity and androgens: Facts and perspectives. Fertil. Steril. 2006, 85, 1319-1340. [CrossRef] [PubMed]

25. Kelly, D.M.; Jones, T.H. Testosterone and obesity. Obes. Rev. 2015, 16, 581-606. [CrossRef] [PubMed]

26. Lamm, S.; Chidakel, A.; Bansal, R. Obesity and Hypogonadism. Urol. Clin. N. Am. 2016, 43, $239-245$. [CrossRef]

27. Kokkoris, P.; Pi-Sunyer, F.X. Obesity and endocrine disease. Endocrinol. Metab. Clin. N. Am. 2003, 32, 895-914. [CrossRef]

28. Bornstein, S.R.; Uhlmann, K.; Haidan, A.; Ehrhart-Bornstein, M.; Scherbaum, W.A. Evidence for a novel peripheral action of leptin as a metabolic signal to the adrenal gland: Leptin inhibits cortisol release directly. Diabetes 1997, 46, 1235-1238. [CrossRef]

29. Pitteloud, N.; Hardin, M.; Dwyer, A.A.; Valassi, E.; Yialamas, M.; Elahi, D.; Hayes, F.J. Increasing insulin resistance is associated with a decrease in Leydig cell testosterone secretion in men. J. Clin. Endocrinol. Metab. 2005, 90, 2636-2641. [CrossRef]

30. Tsai, E.C.; Boyko, E.J.; Leonetti, D.L.; Fujimoto, W.Y. Low serum testosterone level as a predictor of increased visceral fat in Japanese-American men. Int. J. Obes. 2000, 24, 485-491. [CrossRef]

31. Simon, M.; Charles, M.-A.; Nahoul, K.; Orssaud, G.; Kremski, J.; Hully, V.; Joubert, E.; Papoz, L.; Eschwege, E. Association between Plasma Total Testosterone and Cardiovascular Risk Factors in Healthy Adult Men: The Telecom Study 1. J. Clin. Endocrinol. Metab. 1997, 82, 682-685. [CrossRef]

32. Deng, Y.; Zhang, Y.; Li, S.; Zhou, W.; Ye, L.; Wang, L.; Tao, T.; Gu, J.; Yang, Z.; Zhao, D.; et al. Steroid hormone profiling in obese and nonobese women with polycystic ovary syndrome. Sci. Rep. 2017, 7, 1-9. [CrossRef] [PubMed]

Publisher's Note: MDPI stays neutral with regard to jurisdictional claims in published maps and institutional affiliations.

(C) 2020 by the authors. Licensee MDPI, Basel, Switzerland. This article is an open access article distributed under the terms and conditions of the Creative Commons Attribution (CC BY) license (http://creativecommons.org/licenses/by/4.0/). 